\title{
ANÁLISE DRAMATÚRGICA E TEORIA SOCIOLÓGICA
}

\author{
João Gabriel L.C.Teixeira
}

\author{
O mundo todo é um palco. Todos os \\ homens e mulheres são atores e nada \\ mais. Cada qual cumpre suas \\ entradas e saidas, e desempenham \\ diversos papéis durante os sete anos \\ da existência. \\ (William Shakespeare)
}

Antecedentes

A reflexão aqui relatada decorre de oito anos de prática no ensino de Sociologia através do teatro, $\underline{1}$ projeto pedagógico desenvolvido no Departamento de Sociologia da Universidade de Brasília que tinha como objetivo fundamental a busca de uma aprendizagem adquirida a partir da experiência vivenciada, e não apenas ouvida e refletida, pelos alunos envolvidos.

Refiro-me à realização de oito experimentos que, em linhas gerais, visavam criar alternativas para o ensino de Sociologia, utilizando-se de montagens de espetáculos em que temas e questões sociológicas, depois de escolhidos e discutidos, eram finalmente representados por alunos de graduação. $\mathrm{O}$ pressuposto da experiência era que essas experimentações teatrais permitiam aos participantes a vivência de novas situações educativas, proporcionavam a percepção de novos insights e o aparecimento de desafios teórico-metodológicos referentes a temas e objetos sociológicos variados.
Esta reflexão resultou, portanto, da necessidade de elaborar a sustentação teórica dos insights conceituais e metodológicos que emergiam da experiência. Não se tratava mais apenas de delimitar temas e questões sociológicas a serem teatralizadas ou dramatizadas, mas delas extrair elementos teóricos que expandissem o objetivo puramente educativo do projeto e permitissem a formulação de uma metodologia (ou heurística) que pudesse ser aplicada nos processos de construção de determinados objetos sociológicos.

Essa necessidade de teorização originou a idéia de se fazer uma Sociologia através do teatro, que pudesse ou não ser comunicada sob a forma teatral, ou seja, no palco. $\mathrm{Na}$ literatura sociológica encontramos apenas dois precedentes (Coser, 1963; Milstead et al., 1974) com alguma semelhança com o nosso intento. Nos dois casos, porém, seus organizadores empreenderam propostas de ensino da Sociologia através da literatura e da ficção científica, respectivamente, ficando a dramaturgia relegada a apenas duas inclusões (Shakespeare e Ibsen) nos textos ilustrativos 
escolhidos por Coser. Ressalte-se também que não houve da parte deste a preocupação de inserir a encenação do famoso solilóquio de Asyou like it (transcrito no corpo deste texto) ou da cena final deCasa de bonecas como parte da experiência pedagógica no ensino de Sociologia.

\section{A experiência}

O primeiro dos oito experimentos nasceu da necessidade de motivar alunos de graduação na disciplina Sociologia do Trabalho e foi posssibilitado pela implementação, a partir de 1985, pelo curso de Educação Artística da UnB, do projeto "Cometa cenas", que autorizava a qualquer aluno ou grupo de alunos representar uma cena ou apresentar números de dança numa sala de ensaios, em dias previamente marcados.

Um dos itens do programa da disciplina era a ideologia do trabalho, em que o direito à preguiça e o aspecto criativo da ociosidade eram amplamente discutidos à luz de textos clássicos de Max Weber (1967), Paul Lafargue (1980) e Herbert Marcuse (1968). Em decorrência, optou-se pela encenação do primeiro ato da Farsa da boa preguiça (1974), de Ariano Suassuna.

O mote era questionar a moral ascética via a boa preguiça brasileira: de Malazartes a Macunaíma, de Suassuna a Mário de Andrade e deste à poesia de Ascenso Ferreira. 20 contraponto sociológico era municiado por Anthony (1978), que mostra justamente o processo histórico de formação da ideologia do trabalho e esclarece como a ética protestante e a essencialidade do trabalho, na visão marxista, funcionam igualmente para garantir a dominação cultural e a exploração do trabalho humano.

No ano seguinte a disciplina era Sociologia da Educação e o texto de dramaturgia escolhido foi $A$ aurora da minha vida (1982), de Naum Alves de Souza. O experimento visava retratar os conflitos emocionais, geracionais e ideológicos do processo escolar a partir da leitura e discussão de textos freudianos $\underline{3}$ sobre a crueldade infantil e sobre o mito infância infeliz. O objetivo era proferir, no palco, uma aula magna sobre educação escolar.

O exercício da ironia estava presente no mote inspirado pelos versos de Casimiro de Abreu que acompanharam o processo de maturação escolar de muitos brasileiros: "Oh! Que saudades que eu tenho/ da aurora da minha vida/ da minha infância querida/ que os anos não trazem mais [...]". Além disso, as falas e situações da peça de Naum proporcionavam aos participantes a regressão à infância e ao convívio com mestres, pais e colegas.

O terceiro experimento versou sobre a sociologia da família, no âmbito da disciplina Teorias da Socialização. Desta vez o texto de dramaturgia utilizado foi $O$ casamento pequeno-burguês (1919) de Bertolt Brecht. A intenção era exercitar uma teoria crítica da família como instância socializadora. $\mathrm{O}$ mote resultava de um pequeno conselho de Brecht: "De todas as coisas certas, a mais certa é a dúvida".

Depois de questionar a ideologia do trabalho e de revivenciar a escola, nada mais apropriado para enfocar nossos entes familiares do que este texto de Brecht. $O$ casamento pequeno-burguês flagra a família no momento de sua constituição, apreendido segundo a perspectiva anárquicoexpressionista que o autor adotava na época em que escreveu o texto. A peça oferece, enfim, um material humano e empírico imediatamente disponível em seus personagens e situações que favorecem o exercício da dúvida, permitindo a cada participante e espectadortornarse um cientista social distanciado, à maneira de Galileu, que examinava os astros à distância, em seu telescópio.

O quarto experimento utilizou um texto clássico da dramaturgia universal, também da autoria de Bertolt Brecht: $A$ ópera de três vinténs (1928). A peça fora escrita na Berlim da República de Weimar e estava completando, portanto, 60 anos. Nela Brecht utilizou o lupenproleteriat essa escória social! como pretexto para realizar uma réplica mordaz da sociedade londrina de então, expondo o seu escárnio sobre o mundo dos negócios e parodiando a 
hipocrisia religiosa, o casamento romântico e a parcialidade do sistema judicial inglês.

A idéia era explorar os contornos disciplinares da Sociologia Política por meio da encenação de um enredo que mostrava, sobretudo, o conluio que se estabelecia na Londres do início do século entre delinqüentes, policiais e autoridades no sentido de manter-se a corrupção e a impunidade como padrões dominantes de moralidade. $\mathrm{O}$ mote era mostrar situações semelhantes que ocorriam no país naquele ano de 1989, em pleno governo Sarney e após a débâcle do Plano Cruzado.

O pano téorico de fundo foi fornecido por artigo seminal de Costa (1988) que tratava da crise social e moral que o Brasil atravessava, e da conseqüente anomia reinante, à luz dos ensinamentos de Freud (1914) sobre o narcisismo. Por outro lado, Leite et al. (1987) delineavam os contornos de uma sociologia da corrupção e da impunidade. A montagem de A ópera..., portanto, constituiu-se numa contribuição teórico-empírica visando à construção de uma sociologia política da sociedade brasileira contemporânea.

Note-se que, nesse momento, o projeto afastava-se de um mero exercício disciplinar no campo das sociologias específicas e passava a explorar temas candentes e reais, objetivando a reflexão sobre questões e problemas estruturais e conjunturais. Dessa forma, o quinto experimento tratou de tópicos relacionados à religião e à política. As discussões teóricas foram concentradas, basicamente, no cotejamento de dois trabalhos clássicos de Durkheim e Freud no campo explorado: respectivamente, As formas elementares da vida religiosa (1965) e Totem e tabu (1912-13).

O texto dramatúrgico escolhido foi $A$ guerra mais ou menos santa, de Mario Brasini (sem data). Neste caso, o mote era transmitir novos significados e discernimentos sociológicos sobre os fenômenos da doutrinação religiosa, alívio sexual e conchavos políticos e suas inter-relações. A peça representa a luta de um padre para fechar os bordéis de sua paróquia em época de eleições municipais, tendo de disputar a hegemonia política ao mesmo tempo com a mais afluente cafetina local e com o mais poderoso latifundiário.

O sexto experimento tratou de temas da sociologia da adolescência. O suporte teórico era dado, novamente, pela leitura e discussão dos ensinamentos de Freud sobre a sexualidade humana, especialmente em relação ao estágio da puberdade. O texto dramatúrgico foi concebido como colagem, intitulada de Sol sobre o pântano. Baseava-se na peça do alemão Frank Wedekind, O despertar da primavera (1891), seu eixo central, ao qual foram inseridas cenas das peças do brasileiro Nelson Rodrigues que cuidam, de alguma forma, da temática escolhida.

Essa abordagem visava à emergência de novos insights a respeito do conhecimento sociológico sobre o processo de socialização, exigindo mais leitura e discussão sobre os contextos históricos em que as peças foram escritas e os artifícios empregados pelos autores para tratar de problemas como namoro, gravidez, aborto, homossexualidade e suicídio nos enredos.

A encenação teve como conseqüência a recorrente sensibilização estética dos participantes envolvidos, proporcionando o desenvolvimento da sua consciência moral, pois foi concebida para provocar um pavoroso fluxo de consciência proveniente do labirinto inconsciente de cada personagem, para parafrasear Nelson Rodrigues.

O sétimo experimento foi também desenvolvido em duas fases. A primeira consistiu na elaboração de uma colagem visando à montagem de uma revista musical sobre a descoberta/invasão da América, por ocasião das rememorações do seu quinto centenário (1992). A segunda fase consistiu na montagem do script criado para a revista, intitulada de $O$ rebolado de Colombo.

À luz da teoria weberiana da dominação carismática (Weber, 1991), construiu-se o argumento sociológico que, primeiro, enfocava o julgamento do protagonista histórico, conforme produzido na literatura abundante surgida no período, na qual respostas para a questão "herói ou vilão?" eram incessantemente procuradas, para depois buscar 
elaborar algumas respostas para a questão: o evento a ser evocado teria sido uma descoberta ou uma invasão?Levouse em consideração que é parte do conteúdo científico da Sociologia gerar a formação de campos polêmicos (teóricos e metodológicos) nos quais seus estudiosos se movem dialeticamente e fornecem sentido às suas descobertas e explicações.

O oitavo experimento, intitulado de Saint Louis Blues, novamente enfocou a família e as relações familiares, tendo como base a primeira peça do dramaturgo norte-americano Tennessee Williams, a aclamada e clássica $A$ margem da vida (1945), que apresenta ilustrações clarividentes de problemas sociais, candentes em sua natureza, enfrentados por uma família nuclear e parcial (mãe abandonada, filho e filha) sobrevivendo num pequeno apartamento de conjunto residencial popular na cidade de Saint Louis, Estado de Missouri, no final da década de 1930.

$\mathrm{Na}$ construção do texto, foram retirados todos os solilóquios redundantes do script original e mantidos apenas aqueles que enfatizavam a interpretação sociológica de seus eventos e personagens. O fundo social desta peça, ou seja, os efeitos da grande depressão econômica norte-americana e a privação sofrida pelos seus personagens, foi assim sublinhado de modo a mostrar a sua similaridade com problemas sociais vividos atualmente no Brasil.

O processo de recortar o texto original e conceber a sua montagem significou um exercício prático de como transitar dos estágios da interpretação para a compreensão das questões sociológicas enfocadas, exercício quefoi implementado através da dramatização das situaçõesobjeto desse mesmo trânsito. Por outro lado, dados empíricos eram estabelecidos mediante a comparação com condições sociais similares.

Enquanto Saint Louis atravessava os piores momentos da Grande Depressão, os fatos históricos eram ameaçadores: guerra civil e Guernica na Espanha, greves e levantes operários nos Estados Unidos e a iminência da Segunda Guerra Mundial. No Brasil, o aceleramento da inflação e a miséria crescente delineavam um quadro social similarmente sombrio. As dificuldades e a desesperança dos personagens de Williams formavam uma parte visível do nosso cotidiano. Trabalhar com $A$ ̀ margem da vida também implicou a experimentação de uma estética sociológica que resultou na criação de uma poética para a sociologia da família.

Uma análise superficial desses experimentos revela elementos teóricos e metodológicos passíveis de aplicação em experiências semelhantes. Esses elementos dizem respeito, principalmente, à percepção de vários "pentimentos" 4 acontecidos durante o processo de realização das experiências. Os primeiros referiam-se aos níveis de realidade desvendados a partir da revelação de uma variedade de motivos encobridores, tanto entre os participantes como nos personagens que viviam. A experiência estética proporcionando o substrato para o exercício da crítica sociológica. Os demais, em sua grande maioria, diziam respeito aos níveis de discernimento retratados nos graus de transfiguração e mimesis vivenciados pelos participantes.

Não obstante, a pergunta colocada no início deste artigo precisava ser respondida, pois, da forma como a abordagem era transmitida, ficava sempre a questão de se o que se apresentava no palco não era apenas ou mais teatro (arte cênica) propriamente dito, embora com conotações sociais, sociológicas e éticas mais evidenciadas.

\section{Em busca de uma abordagem teórica}

As primeiras insinuações de resposta a esta questão foram encontradas em Robert Nisbet (1976). Este autor achava bastante revelador que a palavra teoria provenha da mesma raiz grega que a palavra teatro (theoria, theatrum). Uma comédia ou tragédia, afirma Nisbet, nada mais é que uma investigação da realidade, não menos uma destilação de percepções e experiências que uma hipótese ou teoria que leve em consideração a incidência variável de assassinatos ou casamentos, por exemplo. Para demonstrá-lo, lembra o famoso monólogo do personagem Jacques em As you like 
it de William Shakespeare, em que este alcançava um nível de compreensão sobre os papéis sociais apenas tardiamente explicitado pelos sociólogos contemporâneos:

O mundo todo é um palco. Todos os homens e mulheres são atores e nada mais. Cada qual cumpre suas entradas e saídas, e desempenham diversos papéis durante os sete anos da existência. Primeiro é a criança que berra e baba nos braços da babá. Depois é o menino chorão que se arrasta como um caracol e faz manha para não ir à escola. Depois é o amante cheio de suspiros que faz baladas tristíssimas para cantar as sobrancelhas da amada. Depois é o soldado com seus estranhos juramentos, barbado feito um bicho, espada pronta a perseguir a glória, mesmo entre a fala em fogo dos canhões. Depois é o juiz de pança ilustre, olhos severos, barba comme il faut, a boca plena de palavras sábias e outras banalidades de ocasião. No sexto ato troca o figurino pelos chinelos de Pantaleão, os óculos plantados no nariz [...] as calças do passado, assim, bufantes, porque já não há carne como dantes, e a voz tonitruante de outros dias se muda num falsete de criança. E enfim começa a cena derradeira, como arremate dessa estranha história, que finda no completo esquecimento, sem olhos, sem memória, sem mais nada. (Ato II, Cena VI)

Após concluir que a afinidade entre a Sociologia e a Arte é que ambas se dedicam a compreender a realidade (no sentido weberiano), ou seja, uma compreensão que entra no reino dos sentimentos, motivações e do espírito, Nisbet afirma que não podemos deixar de lado o fato de que elas criam formas diferenciadas de representar essa realidade, criam espécies de representação ordenada.

A partir dessa congruência, buscou-se explorar as relações entre Sociologia e teatro mediante um cotejo sistemático dos artigos publicados em The Drama Review que relacionassem o teatro através do conceito deperformance e de suas interfaces com a Sociologia Política, em virtude de esta se constituir numa das áreas mais férteis de aplicação da perspectiva dramatúrgica. Chegou-se, assim, ao artigo seminal de Borreca (1993), que apresenta uma exegese muito exaustiva de um campo de explicação sociológica às vezes chamado de dramaturgia, simplesmente, ou de dramatism, ou de análise dramatúrgica, nome adotado como denominador da abordagem que iria finalmente esclarecer, iluminar e desenvolver insights anteriores sobre as relações teóricas e metodológicas entre teatro e Sociologia.

Por ser exaustiva, a resenha de Borreca (1993) facilitou o acesso ao que existe de mais atual na literatura pertinente e tornou mais segura a adoção da perspectiva dos performance studies como desdobramento mais contemporâneo e sofisticado da perspectiva dramatúrgica.

O mencionado cotejamento, por outro lado, identificou os estudos dramatúrgicos e antropológicos de Evreinov (1970), Mead (1962) e Geertz (1973 e 1980), considerados fundadores do campo, e aqueles de outros estudiosos mais recentes, influenciados pelas obras de Burke (1962 e 1968), Goffman (1959 e 1961) e Turner (1974, 1982 e 1986), tais como Schechner (1988 e 1993), que expandiram a apreensão daquele desdobramento, no sentido de incluir as ações do cotidiano, seus efeitos sobre a sociabilidade humana e a constituição dos imaginários coletivos como questões sociológicas específicas que a perspectiva dramatúrgica deveria iluminar.

As idéias dos fundadores serão expostas mais adiante. Por ora, cabe apenas acentuar a influência de Geertz (1973), que em seu famoso estudo sobre as brigas de galo em Bali concluiu que, num nível individual, tal jogo absorvente ("deep play") poderia ser considerado irracional, mas que o mesmo era altamente significativo em termos de identidade social e para os processos de adscrição de status. De acordo com Geertz, somente asperformances que envolvem seus participantes em algum tipo de jogo absorvente são propensas a fazer emergir preocupações relevantes acerca das idéias e códigos fundamentais de uma determinada cultura. A perspectiva dramatúrgica adota que tanto as performances teatrais convencionais como as performances culturais $\frac{5}{}$ constituem-se em tipos similares de "deep play".

Ainda no campo antropológico, a contribuição mais importante provavelmente foi a de Victor Turner. No seu estudo sobre o povo Ndembu, esse autor estabeleceu o conceito de drama social como instrumento para os antropólogos sociais, permitindo, mediante o desenvolvimento de um modelo criado a partir das formas culturais específicas de teatro, a sua utilização em referência a um conjunto maior de manifestações culturais, buscando sobretudo explicar a organização estrutural das mesmas. 
De acordo com Carlson (1996, pp. 21-22), nenhum teórico "tem sido mais instrumental no desenvolvimento da moderna teoria da performance, nem como explorador das relações entre o trabalho prático e téorico na pesquisa teatral e nas ciências sociais do que Richard Schechner". A colaboração entre Turner e Schechner foi das mais frutíferas, especialmente a partir do workshop realizado em Nova York no início da década de 1970, onde os dois autores puderam explorar a relação entre o drama estético (teatro) e o drama social. Deste profícuo encontro também participou Erving Goffman, efetivando a consolidação das bases teóricas dos estudos sobre aperformance.

Conforme menciona Carlson (1996), a partir dessa experiência Turner foi persuadido a admitir que, na verdade, o ator teatral se utiliza das ações conseqüentes da vida social como matéria-prima para a produção do drama estético, ao passo que o ator social se utiliza de técnicas derivadas do teatro para sustentar as ações do drama social, o qual, por sua vez, fornece combustível ao ator teatral.

Schechner, numa frase muito citada, define performance como comportamento restaurado (restored behavior), enquanto qualidade da mesma que não envolve a apresentação de habilidades, mas que tem a ver com o distanciamento entre o self e o comportamento social, semelhante ao que se estabelece entre o ator e o papel que ele desempenha no palco. O distanciamento cria a virtude de os atos poderem ser repetíveis ou restauráveis de formas e em versões variadas. Entre essas, Schechner lista shamanismo, exorcismo, transe, ritual, dança e teatro convencionais, ritos de iniciação, dramas sociais, psicanálise e outras terapias. Essa várias versões consistem em performances porque criam realidades que existem num plano diferenciado em relação à vida cotidiana, mesmo que dela se nutram.

\section{O drama na realidade social}

Encontro ainda mais significativo, porém, no sentido da mencionada busca teorizante, deu-se com a obra de Lyman e Scott (1976), na qual é sistematizada uma série de idéias inspiradoras e legitimadoras que facilitaram, em grande medida, o desvendamento das relações entre os dois temas deste trabalho. Já no prefácio os autores apresentam como epígrafe um trecho de Don Quixote em que Cervantes acentua a perspectiva dramatúrgica, reafirmando, à la Shakespeare (1985), que este mundo é mesmo um palco. .6 Posteriormente, passam a afirmar, à la Nisbet, que a palavra teoria é derivada do termo grego para teatro e que essa derivação sugere que o método apropriado para a teorização foi, desde o começo, dramático (dramatistic) ou dramatúrgico.

Os mais antigos teóricos gregos eram chamados de theoria, termo que se referia (a) a um enviado escolhido para consultar um oráculo; (b) ao corpo de embaixadores delegados do Estado a festividades e jogos; (c) aos espectadores das apresentações teatrais públicas e aos viajantes estudiosos das culturas. Quando um theoriavisitava um oráculo, buscava, na verdade, uma comunicação divina e uma interpretação da mensagem recebida. Assim, consultas a oráculos, festividades e jogos constituíam-se em performances consideradas significativas por serem reveladoras de um tipo de verdade.

A verdade buscada era a aletheia, escondida da visão mas acessível àqueles que adotassem a atitude de um sábio, vidente ou theoria. Para os gregos, as questões humanas podiam ser concebidas como resultados da ação. Uma teoria do humano é uma theoria da ação. Como os filósofos gregos sabiam, uma reificação dessa ação por meio da repetição e textualização é encontrada no drama (dramaturgia). Drama, cujo equivalente grego dransignificava "atuar", é uma imitação ou uma mimesis de uma ação comum. Mais ainda, o drama (teatro), ao proporcionar a oportunidade para uma audiência (theoria) descobrir as verdades encobertas (aletheia) que ele reifica e universaliza, é a ciência social primordial. No drama representa-se ou interpreta-se as inter-relações humanas, e essa representação ou interpretação são fundamentais para quaisquer das ciências sociais (Perinbanayagan, 1985). 
Lyman e Scott prosseguem lembrando que as performances dramáticas, tipicamente, comunicam seus significados mediante a palavra e que as ciências do humano são, em larga escala, estudos das locuções "performativas". Os cientistas sociais que teorizam neste campo devem proceder como os theoria gregos ou como o público de um drama teatral. A realidade social é percebida teatralmente, ou, posto de outra forma, a realidade é drama, a vida é teatro e o mundo social é inerentemente dramático.

Os autores também enfatizam que a abordagem dramatúrgica tem raízes profundas na Psicologia e Sociologia modernas, destacando os trabalhos de Freud, Mead e Goffman: o teatro do inconsciente, o teatro da mente consciente e o teatro da representação do eu, respectivamente. Se em Freud e em Mead a mente é concebida como o local onde os dramas acontecem, precedendo ou causando a ação, em Goffman as ações do cotidiano são concebidas como o proscênio a partir do qual as pessoas poderão desmascarar a identidade que foi forjada nos bastidores, escondido do público.

De acordo com Lyman e Scott, essa orientação dramatúrgica está presente em quase todas as vertentes da obra de Freud. Os conceitos freudianos são derivados dos personagens e mitos das tragédias gregas. Além disso, Freud concebeu a vida mental em três estágios: o inconsciente, o pré-consciente e o consciente. Preocupado com o interesse científico a respeito do dramático e do trágico, povoou estes três estágios (ou palcos) mentais com atores cujos caracteres estão presentes na vida em sociedade: o superego (impositivo e punitivo), o id(imprudente e impudente) e o ego, sempre ocupado em mitigar as demandas do primeiro e a deslocar as energias de ambos em seu próprio benefício. Ademais, em seu método terapêutico, o analista age como dramaturgo e crítico do drama pessoal do paciente, atuando também como uma espécie de diretor clandestino do drama tácito da transferência.

A concepção de Mead (1962) sobre a mente possui paralelos com as noções de certos" dramatistas" sobre prétextos. O dramaturgo concebe o script e o encenador, o cenário de um drama como o pré-texto da performanceconcreta, designada como texto. A eles cabe estabelecer os parâmetros e possibilidades de ação, deixando aos atores sociais as nuanças e modos de representação. A vida mental, para Mead, requer as habilidades de um dramaturgo, de um diretor, de um elenco de atores, de um público e de seus críticos. Consiste em um generalizado monodrama e em dramas naturalistas específicos. Enfim, os teatros da mente que Mead e Freud conceberam, descreveram e criticaram são locais onde performances reais potenciais são concebidas, teatralizadas, ensaiadas e aperfeiçoadas antes, durante e após sua apresentação ao vivo.

Tratando a seguir de Goffman, Lyman e Scott (1976) afirmam que, particularmente em seu trabalho $A$ representação do eu na vida cotidiana, encontramos uma reversão nesse tipo de pensamento. Goffman, que foi o sociólogo que mais se utilizou da metáfora teatral para explicar os processos de interação humana, transferiu o teatro da performance para fora da mente humana e para dentro dos espaços públicos.

Em Goffman, resumindo, o relacionamento humano assume a qualidade de uma máscara. Cada pessoa, assim, se veste de uma persona, e essa persona, por sua vez, deve revelar um eu apropriado para cada ocasião e, ao mesmo tempo, esconder um self que, se revelado, poderia inibir, embaraçar ou distorcer o seu propósito. Segundo o autor, todo ser humano é ciente dessa personificação, mas, de qualquer forma, a meta última dos dramas naturalistas representados no teatro da vida é desvendar o drama escondido, e os atores reais, no teatro secreto da mente.

Para Goffman, a vida em si mesma se transforma na incorporação de uma infinita variedade dos dramas sartreanos relativos à má-fé, ou pelo menos de um suspeito sentido de inautenticidade. Nos dramas goffmanianos da vida, os indivíduos não são apenas o público dos outros, mas devem também atuar, dirigir e criticar. Em suma, sua dramaturgia enfoca a realidade social como um teatro de performances disponível para estudo pelos cientistas sociais e pelos próprios atores sociais. E sugere que a 
consciência da vida como teatro é uma característica empírica e problemática da própria perspectiva do ator social. Note-se, então, que quando as pessoas experienciam uma suspensão de sua crença no naturalismo ou autenticidade da performance que representam para os outros, elas adotam uma abordagem fenomenológica do fundamento dramático da existência humana.

\section{Ontologia e teatrocracia}

Borreca (1993) também lança a questão de se a abordagem dramatúrgica seria puramente metafórica ou se ela possuiria o dom de, realmente, descrever a realidade social. Segundo ele, Burke e Goffman chegaram a conclusões diferentes: Burke (1968) defendia a condição ontológica da perspectiva que ele chamava de "dramatism";-7 Goffman, por outro lado, achava que o paradigma teatral era meramente um artifício retórico ou de manobra, ressalvando, entretanto, que "o mundo todo não é, certamente, um palco, embora as formas cruciais nas quais ele não o é não sejam fáceis de se especificar" (Goffman, 1959, p. 72).

Para Borreca, contudo, empregar esse tipo de terminologia é ter de lidar com seu status ontológico, pois a análise dramatúrgica constitui-se num modo de metaconsciência do mundo. O autor afirma mais ainda: representação política é representação teatral, parafraseando Norman Brown (1966). Uma sociedade política passa a existir quando se articula e produz um representação, isto é, se organiza como teatro, endereçado a um palco no qual os representantes podem realizar a sua performance. Dessa forma, o drama político pode ser ao mesmo tempo a mais tirânica ou a mais libertadora forma de interacionismo simbólico, com a capacidade tanto de nos fazer imergir no mundo político como de nos oferecer uma alternativa para a criação de um mundo bastante diferente. . $^{-}$

Lyman e Scott (1976) fazem notar que, ao usarmos termos como abordagem dramatúrgica e teoria daperformance, estamos apontando para uma perspectiva que envolve tanto características ontológicas como heurísticas, associadas à noção de drama. Destarte, a abordagem metodológica que melhor permitiria o entendimento das representações sociais seria a análise dramatúrgica, da qual a performance theory é derivada. Isto porque, segundo eles, esta perspectiva é a que melhor esclarece as diferenças e as relações que se pode estabelecer entre o stagecraft e o statecraft. A teatrocracia seria, então, o domínio paradigmático para atheoria que estuda o teatro na vida.

Esse domínio paradigmático afirma que a vida em sociedade é teatro e, portanto, a vida política também é teatral e o domínio do teatro pode ser chamado de teatrocracia. Teatrocracia é um termo cunhado por Evreinov (1879-1953), para quem a vida era meramente teatro 2 e todos os eventos ou ações humanas eram cenas. Em sua principal obra, The theatre in life (1927), este autor afirma em determinado momento: "Examine qualquer [...] ramo da atividade humana e você chegará a conclusões semelhantes. Você verá que reis, estadistas, doutores, todos pagam diariamente tributos à teatralidade. Todos acatam os princípios que reinam no palco." (apudTeixeira, 1996, p. 102).

A noção de teatrocracia tem antecedentes no político, historiador, estadista e dramaturgo italiano Machiavelli (1469-1527), para quem stagecraft e statecraft, respectivamente, "ofício de palco" e "ofício de Estado", estavam intimamente relacionados. A abordagem dramatúrgica de Machiavelli para a política colocava uma questão fundamental: qual a relação entre aparências e realidades? Para ele, a política, como a arte de obter e manter o poder, torna-se uma arte dramática, representada num cenário para um público desejadamente aquiescente. Mais especificamente, para ele a política torna-se a arte principesca de gerenciar aparências (imagens) públicas.

\section{Considerações finais}

Retornando à questão que orientou esta reflexão, e parafraseando Turner (1982, p. 108), conclui-se que um drama social, quando mostrado num palco (teatralizado) 
com intenções outras que o mero divertimento embora este seja sempre um de seus objetivos, é um metacomentário, explícito ou implícito, espirituoso ou não, sobre as grandes questões sociais do contexto em que é realizado. Foi isto que a experiência narrada procurou demonstrar.

As mensagens e retóricas dos dramas estetizados se alimentaram da estrutura processual dos dramas sociais enfocados e providenciaram a sua pronta restauração. Nos casos encenados, essa estrutura processual foi revivenciada, evidenciada e facilitada através da instauração de uma diversidade de "jogos absorventes". Essa restauração dos diversos dramas sociais contribuiu em larga escala para o aprofundamento do conhecimento sociológico sobre os campos disciplinares ou temas enfocados em cada experimento encenado.

Os seres humanos aprendem essencialmente através da experiência, afinal de contas, e a experiência humana mais profunda talvez se realize no teatro. Tanto naquele teatro apresentado num palco como naquele apenas dramatizado no cotidiano da vida social, mas, sobretudo, no processo de circulação e oscilação de sua mútua e incessante transformação.

A experiência demonstrou, enfim, que é enorme a tarefa de criar novas articulações teóricas e conceituais que possam dar conta da delimitação de outros processos e questões sociais e transformá-los em objetos sociológicos definidos. No sentido de expandir os horizontes da compreensão sociológica do teatro na vida, a tarefa sociológica supõe o desvendamento da natureza e das operações dos processos dramáticos na vida cotidiana. Isto facilitaria a análise de como o homem e as coletividades fazem quando "escrevendo", "escolhendo elenco", representando, interpretando e criticando a vida dramática de cada um. Assim, tanto o estudioso como o ator assumiriam a patente de theoria.

A perspectiva dramatúrgica, quando associada à realização de determinadas experiências estéticas, não apenas aduz aspectos ontológicos da vida social como também sublinha, teoricamente, a conseqüente criação de uma estética cognitiva. A experiência aqui narrada, em linhas gerais, também demonstrou a existência de uma variedade de instrumentos e equipamentos artísticos utilizáveis nesse processo de criação.

A estética cognitiva assim construída apresenta uma série de vantagens epistemológicas, dentre as quais se destaca o fato de ela poder fornecer uma variedade de elementos exigidos para a emergência de uma estética sociológica que normalmente se encontra suprimida da maioria dos processos metodológicos corriqueiros utilizados nas investigações sociológicas convencionais. Outra vantagem seria a de contribuir substancialmente para o surgimento de uma poética para a Sociologia (Brown, 1977). Argumentase que essa poética atribuiria uma aura bem mais "glamourosa" à ciência sociológica.

Por outro lado, verifica-se que mesmo quando associada à realização estética, a perspectiva dramatúrgica não suprime a utilização dos instrumentos canônicos de observação, interpretação e construção dos recortes sociológicos de objetos específicos. O mesmo pode ser afirmado com relação aos produtos das investigações realizadas. Estes podem se apresentar sob as formas tradicionais escritas (artigos e livros), mediatizados (vídeo, televisão e cinema) ou ao vivo (leituras dramáticas, peças teatrais, performances musicais ou espetáculos de dança, por exemplo). Cada uma dessas formas apresentando visões diferenciadas de um mesmo processo estético-sociológico, seja na abordagem adotada, nos aspectos visados ou nos níveis de compreensão ou "pentimentos" atingidos.

Desse modo, a análise dramatúrgica associada à estética cognitiva contribui eficazmente para estabelecer a afinidade essencial entre a Sociologia e a Arte a que se referia Nisbet (1976). A primeira fornecendo o rigor acadêmico necessário à investigação teórica e a segunda criando a possibilidade de uma teoria sociológica que seja ao mesmo tempo objetiva e subjetiva. A estética cognitiva também fornece uma série de categorias e conceitos-chave alguns dos quais foram restaurados no decorrer desta reflexão que cuidam de alimentar a compreensão dessa subjetividade. 
A associação da análise dramatúrgica às experimentações estéticas, por fim, contribui significativamente para a construção de paradigmas que tornam a experiência humana mais compreensível, os quais, além de serem validados cientificamente, são humanamente mais significativos.

\section{NOTAS}

1 A propósito, ver Teixeira (1986, 1991, 1992a, 1992b, 1994, 1995 e 1997) e os vídeos Ensinando Sociologia pelo teatro I, II, III, IV e $V$, produzidos em colaboração com o Centro de Produção Cultural e Educativa (CPCE) da Universidade de Brasília.

2 O próprio Suassuna, na introdução à primeira edição da peça, respondendo às críticas negativas dos conservadores e marxistas ao seu trabalho, afirmou: "A meu ver, a Farsa da boa preguiça tem dois temas centrais. Nela não defendo indiscriminadamente a preguiça coisa que, aliás, não poderia fazer, pois ela é um dos `sete vícios capitais' do Catecismo. De fato, creio que isto fica bem claro na peça. No teatro antigo havia uma convenção segundo a qual, no final da história, o autor podia dar sua opinião sobre o que acontecera no palco. Era a chamada 'licença' ou 'moralidade'. Pois bem. Na licença da Farsa, numa das estrofes finais do terceiro ato, dizia um dos personagens: Há uma preguiça com asas,/ outra com chifres e rabo./ Há uma preguiça de Deus/ e outra preguiça do Diabo."

3 Especialmente "Três ensaios sobre a teoria da sexualidade" (1905), "O esclarecimento sexual das crianças" (1907) e "Moral sexual civilizada e doenças nervosas modernas" (1908), reunidos na Edição standard brasileira das obras psicológicas completas de Sigmund Frend, Rio de Janeiro, Imago.

4 "Pentimento" é uma palavra de origem italiana que pode designar repetência, correção ou o reaparecimento, numa pintura, de um desenho que havia sido pintado por cima. Pode também significar dor ou remorso e ainda indicar uma mudança de idéia, proposição ou opinião. Aqui "pentimento" está sendo utilizado no mesmo sentido metafórico a que se refere a romancista e dramaturga norteamericana Lilian Hellman (1906-1984) na epígrafe de suas memórias Pentimento, um álbum de retratos (1973):" À medida que o tempo passa, a tinta velha em uma tela muitas vezes se torna transparente. Quando isso acontece, é possível ver, em alguns quadros, as linhas originais, uma criança dá lugar a um cachorro e um grande barco não está mais em mar aberto. Isso se chama pentimento, porque o pintor se arrependeu, mudou de idéia".

5 MacAloon (1984, p. 1) as define como "ocasiões nas quais, enquanto cultura ou sociedade, refletimos e nos definimos sobre nós mesmos, dramatizamos nossos mitos coletivos e história, apresentamo-nos alternativas e eventualmente mudamos de alguma forma permanecendo os mesmos em outras."

6 Burns (1972) recorda que Platão já fazia uso da metáfora do Theatrum Mundi e que a idéia de Petronius de que Totus mundum agit histrionem era apenas uma versão da mesma que depois foi parafraseada e estendida, sendo usada até como inscrição na entrada do famoso Globe Theatre de Shakespeare.

7 Burke (1968, p. 448) defendia que o "dramatism" é tanto um método de análise como uma ontologia em que o "drama é empregado não como uma metáfora mas como uma forma fixa que nos ajuda a descobrir quais são as reais implicações dos termos `ato' e `pessoa'". Para Burke, crítico literário, filósofo, semanticista e psicólogo social, qualquer afirmação sobre motivações humanas deve responder a cinco questões que levam aos cinco termos-chave do "dramatism": o que foi feito (ato), quando e onde foi feito (cena), quem o fez (agente), como o fez (agência) e por que foi feito (propósito). São estas as principais idéias que o conectam à teoria contemporânea da performance.

8 Segundo ainda Borreca (1993), o que a dramaturgia política faz ou pode fazer é descrever o impulso triádico (personagem-palco-espectador) ao qual a arte teatral está conectada. Quando consegue fazer isso, ela 
terá reforçado o teatro como atividade essencial não apenas na vida social mas como realização formal, refletindo, refratando e cristalizando as tríades do drama social e político.

2 Ver, a respeito de sua obra, Golub (1984). Ver também o capítulo "O eterno show" do livro clássico de Evreinov, The theatre in life, em Teixeira (1996), onde foi publicado pela primeira vez no Brasil.

\section{BIBLIOGRAFIA}

ANTHONY, P.D. (1978), The ideology of work. Londres, Tavistock Publications.

BORRECA, A. (1993), "Political dramaturgy: a dramaturg's (re)view". The Drama Review, 37, 1, Summer.

BROWN, N. (1966), Love's body. Nova York, Random House.

BROWN, R.H. (1977), A poetic for Sociology. Toward a logic of discovery for the buman sciences.Chicago/Londres, The University of Chicago Press.

BURKE, K. (1962a), A grammar of motives. Cleveland, Ohio, Meridian.

(1962b), A rhetoric of motives. Cleveland, Ohio,

Meridian.

(1968), "Dramatism". The International

Encyclopedia of Social Sciences, vol. 7, Londres, MacMillan.

BURNS, E. (1972), Theatricality. A study in convention in the theatre and in social life. Londres, Longman.

CARLSON, M. (1996), Performance, a critical introduction. Londres/Nova York, Routledge.

COSER, L.A. (ed.). (1963), Sociology through Literature. Englewood Cliffs, NJ, Prentice Hall.
COSTA, J.F. (1988), "Narcisismo em tempos sombrios", in Joel Birman (coord.), Percursos na história da Psicanálise, Rio de Janeiro, Livraria Taurus Editora.

DURKHEIM, E. (1965), The elementary forms of religious life. Nova York, The Free Press [1ª ed. 1912].

EVREINOV, N. (1970), The theater in life. Nova York, Benjamim Bloom [1ª ed. 1927].

FREUD, S. (1912-13), "Totem e tabu", in Edição standard brasileira das obras psicológicas completas de Sigmund Freud, Rio de Janeiro, Imago.

(1914), "Sobre o narcisismo", in Edição standard brasileira das obras psicológicas completas de Sigmund Freud, Rio de Janeiro, Imago.

GEERTZ, C. (1973), "Deep play. Notes on Balinese cockfight", in C.Geertz, The interpretation of cultures. Selected essays, Nova York, Basic Books.

(1980), NeGARA: the theatre State in 19th century Bali. Princeton, NJ, Princeton University Press.

GOFFMAN, E. (1959), The presentation of self in everyday life. Nova York, Doubleday \& Co.

. (1961), Encounters: two studies in the sociology of interaction. Indianapolis, Bobbs-Merril.

GOLUB, S. (1984), Evreinov: the theater of paradox and transformation. Ann Arbor, University of Michigan Research Press.

HELLMAN, L. (1973), Pentimento, um álbum de retratos. São Paulo, Círculo do Livro.

LAFARGUE, P. (1980), O direito à preguiça. São Paulo, Kairós.

LEITE, C. Barroso et al. (1987), Sociologia da corrupção. Rio de Janeiro, Jorge Zahar. 
LYMAN, S.M. e SCOTT, M.B. (1976), The drama of social reality. Nova York, Oxford University Press.

MACALOON, J.J. (ed.). (1984), Rite, drama, festival, spetacle: rehearsals toward a theory of cultural performance. Philadelphia, Institute for the Study of Human Issues.

MARCUSE, H. (1968), Eros e civilização. Rio de Janeiro, Zahar.

MEAD, G.H. (1962), Mind, self and society from the standpoint of a social behaviorist. Chicago, University of Chicago Press.

MILSTEAD, J.W. et al. (1974), Sociology through science fiction. Nova York, St. Martin's Press.

NISBET, R.A. (1976), Sociology as an art form. Nova York, Oxford University Press.

PERINBANAYAGAN, R.S. (1985), Signifying acts: structure and meaning in everyday life. Carbondale/Edwardsville, Southern Illinois University Press.

SCHECHNER, R. (1988), Performance theory. Nova York, Routledge.

(1993), The future of ritual: writings on culture and performance. Nova York, Routledge.

TEIXEIRA, J.G.L.C. (1986), "O teatro como tema sociológico e trama de vivência e ensino". Humanidades, Ano V, 28.

(1991), "Sociologia se aprende no palco?". Ciência Hoje, 13, 76.

(1992a), "Sociologia e teatro". Série Sociológica,

Departamento de Sociologia, Universidade de Brasília, 98.

. (1992b), "Theater as a teaching procedure in Sociology". Clinical Sociology Review, 12.
. (1994), "Saint Louis Blues. Um ensaio teatral e sociológico sobre a solidão humana". Série Sociológica, Departamento de Sociologia, Universidade de Brasília, 123. - (1995), "Socialização e estética: mais que uma interseção disciplinar", in S. Adorno (org.), A Sociologia entre a modernidade e a contemporaneidade, Porto Alegre, Editora da UFRGS/Sociedade Brasileira de Sociologia.

(org.). (1996), Performáticos, performance e sociedade. Brasília, Ed. da UnB.

(1997), "As possibilidades da análise dramatúrgica no ensino de Sociologia". Série Sociológica, Departamento de Sociologia, Universidade de Brasília, 133.

TURNER, V.W. (1974), Dramas, fields and metaphors: symbolic action in buman society. Ithaca, Cornell University Press.

. (1982), From ritual to theater: the buman seriousness of play. Nova York, Performing Arts Journal.

. (1986), The anthropology of performance. Nova York, Performing Arts Journal.

WEBER, M. (1967), A ética protestante e o espirito do capitalismo. São Paulo, Pioneira.

(1991), Economia e sociedade. Brasília, Ed. da

UnB.

Peças de teatro citadas

BRASINI, Mario. (s/d.), A guerra mais ou menos santa. São Paulo, Brasiliense.

BRECHT, Bertolt. (1978), A respectable wedding. Londres, Methuen Ltd.

(1986), The three-penny opera. Londres, Methuen Ltd.

RODRIGUES, Nelson. (1981), "Os sete gatinhos", "Álbum de família", "A valsa n. 6", "Viúva, porém honesta" 
e "O anti-Nelson Rodrigues", in Teatro Completo de Nelson

Rodrigues, 4 vols., Rio de Janeiro, Nova Fronteira.

SHAKESPEARE, William. (1985), Uma peça como você gosta (As you like it). Tradução e adaptação de Geraldo Carneiro. Rio de Janeiro, O Tablado, Cadernos de Teatro.

SOUZA, Naum Alves de. (1982), A aurora da minha vida. São Paulo, M.G.Editores Associados.

SUASSUNA, Ariano. (1974), Farsa da boa preguiça. Rio de Janeiro, Livraria José Olympio Editora.

WEDEKIND, Frank. (1973), O despertar da primavera. Lisboa, Editorial Estampa/Seara Nova [1 $1^{\text {a }}$ ed. 1891].

WILLIAMS, Tennessee. (1968), À margem da vida. 